UDC 316.354

LBC 60.54

\title{
INSTITUTIONALIZATION OF THE PROFESSIONAL COMMUNITY OF TRUCK DRIVERS \\ (ON THE EXAMPLE OF THE ASSOCIATION OF TRUCKERS OF YAKUTIA)
}

\author{
Maria E. Osipova \\ M.K. Ammosov North-Eastern Federal University, Yakutsk, Russian Federation
}

\begin{abstract}
The impact of the institutionalization of the professional association of truck drivers-truckers of Yakutia on the formation and development of their civic position is analyzed in the article. The paper identifies the main forms of socio-political participation of the professional community of long-distance drivers in Yakutia. for this purpose, we used official documents, data from field studies (2017-2019) conducted by the author in Yakutsk and Tattinsky ulus of the Republic of Sakha (Yakutia); the author conducted a content analysis of materials of the association of Yakut truckers and mass media published in open access on the internet. The article deals with the all-Russian strike of truck drivers against the introduction of the "Platon" system in 2015, which covered dozens of regions of the country. The strike is considered as one of the prerequisites for the formation of a civil position of the truck drivers community. A key factor in the development of citizenship of Yakut truckers was the creation of the public organization "The Association of Truckers of the Republic of Sakha (Yakutia)", which marked the beginning of the institutionalization of this professional group. The study revealed that the community of truck drivers is characterized by the following features: civic consciousness of the professional community, social activity, the ability to bear social responsibility in conditions of insufficient existing state measures to support the population of remote and hard-to-reach settlements. Correlation of professional and social activity of truckers of Yakutia is revealed. The content and nature of the work of truck drivers, which are associated with the provision of life in the North and in the Arctic, determine their value orientations and civic position. The conclusion is formulated: the successful process of institutionalization of the professional community has an impact on the formation of the civic position of truck drivers in the region. The author believes that further study of the social practices of professional communities is a promising direction in the context of the development of civil society.
\end{abstract}

Key words: truckers, drivers, professional community, professional association, institutionalization, civil society, social activity, Republic of Sakha (Yakutia).

УДК 316.354

ББК 60.54

\section{ИНСТИТУЦИОНАЛИЗАЦИЯ ПРОФЕССИОНАЛЬНОГО СООБЩЕСТВА ВОДИТЕЛЕЙ ГРУЗОВОГО ТРАНСПОРТА (НА ПРИМЕРЕ АССОЦИАЦИИ ДАЛЬНОБОЙЩИКОВ ЯКУТИИ)}

\footnotetext{
Мария Егоровна Осипова

Северо-Восточный федеральный университет им. М.К. Аммосова, г. Якутск, Российская Федерация

Аннотация. В статье анализируется влияние институционализации профессионального объединения водителей грузового транспорта-дальнобойщиков Якутии на формирование и развитие их гражданской позиции. На основании официальных документов, данных полевых исследований с 2017 по 2019 г., проведенных автором в г. Якутск и Таттинском улусе Республики Саха (Якутия), а также контент-анализа материалов ассоциации якутских дальнобойщиков и средств массовой информации, размещенных в открытом доступе в сети Интернет, выявлены основные формы социально-политического участия профессионального сооб-
} 
щества водителей-дальнобойщиков Якутии. В качестве одной из предпосылок становления гражданской позиции сообщества дальнобойщиков рассматривается всероссийская забастовка водителей грузового транспорта против введения системы «Платон», стартовавшая в 2015 г. и охватившая десятки регионов страны. Отмечается, что ключевым фактором развития гражданственности якутских дальнобойщиков стало создание общественной организации «Дальнобойщики Республики Саха (Якутия)», обусловившее начало институционализации данной профессиональной группы. Выявлено, что сообществу водителей грузового транспорта характерны такие особенности как гражданское самосознание профессионального сообщества, социальная активность, способность нести социальную ответственность в условиях недостаточности действующих государственных мер поддержки населения отдаленных и труднодоступных поселений. Наблюдается корреляция профессиональной и социальной деятельности дальнобойщиков Якутии. Содержание и характер труда водителей большегрузов, связанные с обеспечением жизненно необходимых процессов на Севере и Арктике, детерминируют их ценностные ориентации и гражданскую позицию. Сделаны выводы о влиянии институционализации профессионального сообщества на формирование гражданской позиции водителей грузового транспорта в регионе. Представляется перспективным дальнейшее изучение социальных практик профессиональных сообществ в контексте развития гражданского общества.

Ключевые слова: дальнобойщики, водители, профессиональное сообщество, профессиональная ассоциация, институционализация, гражданское общество, социальная активность, Республика Саха (Якутия).

\section{Введение}

Одним из основополагающих принципов современного гражданского общества является возможность создания и развития ее членами механизма самоуправления для защиты своих интересов и прав. Некоммерческие организации способствуют обеспечению стабильности, устойчивости социальной политики на всех уровнях. Особое место среди множества общественных формирований сегодня занимают профессиональные ассоциации, деятельность которых оказывает все большее воздействие на жизнедеятельность социума.

K настоящему времени накоплено немало научных работ, посвященных изучению социологии труда. Огромный вклад в разработку теоретических концепций и подходов внесли отечественные социологи П.А. Сорокин, В.А. Ядов, В.Г. Подмарко, Ж.Т. Тощенко, В.А. Мансуров, О.И. Шкаратан, В.Н. Шубкин. Подробному рассмотрению профессий в контексте социально-гуманитарного знания посвящены современные исследования Р.Н. Абрамова, Г.Б. Кораблевой, О.В. Лукша, И.П. Поповой, П.В. Романова, Е.Р. Ярской-Смирновой и др.

Одним из крупных профессиональных сообществ в Республике Саха (Якутия) является объединение дальнобойщиков - водителей-предпринимателей, занятых грузоперевозками. Дальнобойщики играют важную роль в региональной социально-экономической системе. Именно автомобильным транспортом сегодня перевозится более 70 \% всех грузов в республике [Сводный годовой доклад... web]. На водителях-дальнобойщиках лежит большая ответственность: от своевременной доставки товаров и услуг зависит жизнедеятельность населения и стабильное функционирование организаций социальной сферы, жилищно-коммунального хозяйства и энергетики в отдаленных и труднодоступных районах Якутии. Гарантированное обеспечение завоза грузов (продукции) в районы с ограниченными сроками завоза грузов предусмотрено государственной программой Республики Саха (Якутия) [Указ Главы РС(Я) от 06.11.2019... web]. Труд водителей приобретает особую значимость в специфических условиях региональной транспортной системы: экстремальные природно-климатические условия, низкая обеспеченность дорожной инфраструктуры, сезонность транспортного сообщения. Данные обстоятельства обуславливают необходимость упорядочивания взаимодействия субъектов процесса транспортировки грузов.

В 2017 г. водители большегрузов Якутии организовали свой профессиональный союз. За время существования ассоциации сообщество дальнобойщиков разработало различные социальные технологии для реализации своих профессиональных и гражданских интересов.

Материалом для анализа послужили нормативные правовые акты Министерства транспорта и дорожного хозяйства Республики Саха (Якутия), официальные документы 
общественной организации «Дальнобойщики Республики Саха (Якутия)», полевые наблюдения с 2017 по 2019 г., проведенные автором в г. Якутск и Таттинском улусе Республики Саха (Якутия), контент-анализ информации, размещенной в открытом доступе Интернет на площадках различных средств массовой информации.

\section{Система «Платон» как фактор артикуляции профессиональных интересов дальнобойщиков}

Одним из ярких образцов артикуляции корпоративных интересов профессионального сообщества за последнее десятилетие стала всероссийская забастовка водителей грузового транспорта-дальнобойщиков против введения так называемой системы «Платон».

Система «Платон», подразумевающая взимание платы с автомобилей, максимальная разрешенная масса которых свыше 12 тонн, была введена Правительством страны в ноябре 2015 года. Планы возместить через систему «Платон» вред, причиняемый большегрузами федеральным дорогам, вызвали волну критики и недовольства среди ее потенциальных плательщиков - индивидуальных предпринимателей, занятых грузоперевозками. В десятках регионов (Дагестан, Волгоградская область, Ростовская область, Башкортостан, Москва и Московская область, Кировская область, Свердловская область, Новосибирская область, Карелия и др.) прошли протесты водителей большегрузов с требованием отмены «Платона». Основными координаторами движения являлись Межрегиональный профсоюз водителей-профессионалов и коммунистическое рабочее движение «Рабочий путь» [Сборов web]. Плакаты и баннеры, выезд машин на дороги и обочины, парковка машин вдоль трасс, многокилометровые пробки, так называемая итальянская забастовка, когда автомобильные дороги блокируются длинными колонами тягачей и прицепов, из-за чего резко снижается скорость движения автотранспорта, - вот некоторый перечень форм протеста российских дальнобойщиков [Погребняк web].
В поддержку вспыхнувших по стране протестных акций против введения системы «Платон» выступили десятки предпринимателей-дальнобойщиков Якутии. В декабре 2015 г. водители большегрузных автомобилей совместно с членами региональной коммунистической партии вышли на пикет в центре Якутска. Участники акции, собравшись у Дома правительства республики, развернули плакаты с надписями «Дальнобойщики Якутии против системы “Платон”», «Заплатит дальнобойщик - подорожает все!», «Автодор - это автоВОР», «“Платон” - кормушка олигархов», «Ротенберг и “Платон” - грабители на дорогах России», «Правительство Медведева в отставку! Крышует Платон...» и др. [Дальнобойщики Якутии... web]. Пикетчики потребовали у правительства республики отменить нововведенный транспортный налог. По мнению участников пикета, введение системы «Платон» провоцирует удорожание грузоперевозок и, как следствие, приведет к росту цен в республике. Водители пригрозили срывом «северного завоза»перевозки социально значимых грузов в труднодоступные арктические улусы (районы), где отсутствуют дороги круглогодичного пользования. Опасения дальнобойщиков подтверждаются региональными реалиями.

К федеральным дорогам, за пользование которых предполагалось взимание платы, в республике приравнены сезонные дороги - так называемые автозимники - автомобильные дороги, представляющие собой дорожное полотно из промерзшего льда [Argounova-Low 2012, 74]. То есть фактически водители были вынуждены платить за пользование временными, не гарантирующими безопасность движения дорогами. Кроме того, учитывая то, что по автозимникам осуществляется перевозка тысяч тонн грузов в арктическую зону республики, «Платон» мог отразиться на стоимости жизнеобеспечивающих товаров и услуг.

Солидаризировавшись с водителями из других регионов, якутские дальнобойщики продемонстрировали собственную позицию в условиях кризисной ситуации. Против введения системы выступили дальнобойщики в нескольких районах Якутии [Якутские дальнобойщики... web]. Однако прямого и откры- 
того диалога водителей с властью установлено не было. Примечательно, что вслед за акциями дальнобойщиков официальными источниками публиковались статьи о важности введения системы «Платон» [Алексеев web].

В 2008 г. задолго до событий вокруг «Платона» протестная акция с участием 250 дальнобойщиков прошла в г. Нерюнгри. Водители большегрузов требовали повысить тарифы на грузоперевозки. Тогда на 7 дней были приостановлены грузоперевозки из Нерюнгри в Якутск. Акция была прекращена после собрания с участием представителей Министерства транспорта и связи Республики Саха (Якутия), которые постановили, что проблема нерюнгринских дальнобойщиков будет решаться на уровне республиканского правительства [Акция протеста... web]. В том же году в Нерюнгри было организовано некоммерческое партнерство «Союз водителей дальнобойщиков». Сведения о деятельности союза в сети Интернет автором не обнаружены. Известно, что члены союза планировали принять участие в согласованной акции против завышенных цен на бензин [Нерюнгри, Республика СахаЯкутия web].

В целом протестные акции в республике проходили мирно, умеренно, без нарушений установленного законодательством порядка проведения массовых мероприятий. В условиях угрозы социально-экономическим интересам сообщество водителей грузового транспорта смогло сплотиться, выработать требования и стратегию действий. Очевидно, что главным инструментом защиты социально-трудовых прав и интересов водителей грузового транспорта уже с 2008 года являлась самоорганизация, на повестке которой были вопросы федерального значения. Однако кризисные ситуации не смогли объединить большее количество людей и масштабироваться по всей территории республики.

Автор не исключает вероятности того, что некоторые протестные акции с участием дальнобойщиков, проходившие в Якутии, не были зафиксированы средствами массовой информации, поэтому они не нашли отражение в настоящей статье.

\section{«Дальнобойщики Республики Саха} (Якутия)»: цели, задачи, деятельность

Значимым событием для водителей большегрузов Якутии стало создание региональной общественной организации «Дальнобойщики Республики Саха (Якутия)» в 2017 г., обусловившее начало институционализации профессии водителей грузового транспорта. Идея создания организации принадлежала объединению дальнобойщиков Чурапчинского улуса, ранее проводившему в своем районе «Фестиваль грязи», приуроченный к закрытию сезона грузоперевозок [Ассоциация дальнобойщиков... web]. Всего, по информации Евдокии Дьячковской, председателя организации, в ассоциации состоит более 100 водителей большегрузов. Основными целями ассоциации являются всесторонняя координация деятельности членов организации, профессиональное развитие и повышение авторитета водителей грузового транспорта.

Направления деятельности организации «Дальнобойщики Республики Саха (Якутия)» можно разделить на следующие основные группы:

- организационно-консультационная (расширение деловой активности; оказание консультационной помощи; разработка и совершенствование методического и технического обеспечения деятельности; содействие установлению, поддержанию и развитию партнерских отношений с организациями и объединениями в области проведения и организации автомобильных перевозок грузов; проведение семинаров, совещаний, выставок);

- законотворческая (участие в выработке государственными органами решений и принятия нормативных правовых актов в сфере перевозочной и транспортно-экспедиционной деятельности; разработка стандартов и рекомендаций, касающихся взаимоотношений между организациями-перевозчиками грузов в автомобильном сообщении с одной стороны, и их клиентами - с другой; изучение и анализ предпринимательской деятельности в сфере оказания транспортных услуг по организации и проведению автомобильных перевозок грузов, применение действующих в данной области нормативных правовых актов и внесение предложений по их совершенство- 
ванию; участие в разработке и осуществлении программ по развитию системы образования, подготовки и переподготовки кадров в сфере грузоперевозок);

- экономическая (содействие в привлечении инвестиций для финансирования перспективных проектов и мероприятий, а также в поиске надежных партнеров, разработка и сопровождение совместных инвестиционных программ);

- информационная (освещение деятельности в средствах массовой информации; создание информационных баз, обеспечивающих эффективную деятельность на рынке транспортных услуг; разработка и издание собственного периодического издания и других печатных материалов в целях пропаганды и информационного обеспечения предпринимательской деятельности в сфере грузоперевозок).

Приоритетную роль в деятельности общественной организации занимает сотрудничество и взаимодействие с правительственными структурами. По инициативе организации возобновилось обсуждение проблем процесса грузоперевозок в северные и арктические улусы, применения порядка системы «Платон» в условиях Севера и Арктики. На круглых столах и совещаниях правительства региона заслушивались доклады организации о проблеме устаревания автомобильного парка, развития дорожной инфраструктуры. Дальнобойщики Якутии также выступали с законодательными инициативами к федеральному закону от 12 января 1995 г. № 5-Ф3 «О ветеранах» с предложением о присвоении звания «Ветеран труда»водителям-мужчинам, осуществляющим предпринимательскую деятельность в районах Крайнего Севера и приравненных к ним местностях не менее 30 лет, к федеральному закону от 5 апреля 2013 г. № 44-Ф3 «О контрактной системе в сфере закупок товаров, работ, услуг для обеспечения государственных и муниципальных нужд» с целью смягчения требований конкурса к индивидуальным предпринимателям, занимающихся грузоперевозками.

В 2017 году Министерство транспорта и дорожного хозяйства Республики Саха (Якутия), региональная торгово-промышленная палата и союз якутских дальнобойщиков провели 1-й Съезд дальнобойщиков Якутии. На повестку съезда было вынесено обсуждение комплекса вопросов, связанных с функционированием грузового автомобильного транспорта, определение путей взаимодействия дальнобойщиков с бизнесом, органами власти, надзорными органами, а также создание системы правовой и информационной поддержки для автомобилистов. В мероприятии приняли участие более 300 дальнобойщиков из 17 улусов [Состоялся 1-й Съезд... web].

За время существования общественной организации дальнобойщиков Якутии удалось структурировать отношения профессионального сообщества с органами власти, систематизировать нормы и принципы осуществления профессиональной деятельности, обратить внимание общественности к проблемам в сфере автомобильных грузоперевозок. Организация стала институтом представительства и защиты функциональных интересов и прав предпринимателей в исполнительных и законодательных органах власти, отраслевых ведомствах и предприятиях.

\section{Гражданская активность дальнобойщиков}

В отдельных улусах сформировались свои институциональные формы организации деятельности водителей грузового транспорта. Так, например, дальнобойщики Таттинского улуса организовали независимый союз водителей-дальнобойщиков «Таатта дальнобой». Для практики этого союза характерно альтруистическое поведение. В 2016 году водители улуса к 100-летнему юбилею наслега посадили 100 деревьев в центре села, в следующем году общественная организация на собственные средства возвела в районном центре с. Ытык-Кюельсквер «Алгыстаах айан» (Благословенный путь). Позже в этом сквере появилась полка для буккроссинга, также установленная водителями-дальнобойщиками [Предприниматели Таттинского улуca... web]. Водители улуса оказывают посильную помощь многодетным семьям, землякам, попавшим в трудную жизненную ситуацию. Активная социальная работа ассоциации награждается общественным признанием, почетом. В 2018 г. дальнобойщик из Таттинского 
улуса Никифор Кутугутов был выдвинут на всенародную премию «Гордость Якутии» за высокие профессиональные достижения и занял 3 место в номинации «Предприниматель» [Булчукей web].

К другим практикам общественно-политического участия водителей грузового транспорта можно отнести агитационную деятельность в период избирательных кампаний в республике. Так, в августе 2018 г. на традиционном празднике ысылах, организованном дальнобойщиками Якутии в Таттинском улусе, во время общего фотографирования участники мероприятия растянули перед объективами фотокамер предвыборный баннер с представителем партии «Единая Россия» Айсеном Николаевым, одним из претендентов на пост главы республики. В период проведения избирательной кампании в поддержку Айсена Николаева по социальным сетям также были распространены тематические видеоматериалы с участием водителей большегрузов, призывающих поддержать кандидата. Во время данной предвыборной кампании в районах параллельно проходила кампания по выборам глав муниципальных районов. Кандидата на пост главы Чурапчинского улуса Андрея Ноговицына поддержали местные дальнобойщики, призывавшие в социальных сетях проголосовать за своего земляка. По некоторым сведениям, Андрей Ноговицын ранее занимался грузоперевозками. В том году оба кандидата выиграли выборы.

К ресурсам влияния водителей грузового транспорта также относится возможность информационного воздействия. В 2019 г. ассоциация водителей распространила по социальным сетям видеоматериал «Мы за Ленский мост!» в поддержку строительства моста через реку Лена, основной транспортной артерии региона, по которой водители доставляют социально важные продукты и товары в районы Севера и Арктики. Переговоры о реализации проекта ведутся с 2013 г., однако окончательное решение по строительству мостового перехода по сей день не принято.

\section{Результаты и обсуждение}

После серии масштабных выступлений водителей грузового транспорта против вве- дения системы «Платон» в 2015 году правительство пошло на уступки: на некоторое время были «заморожены» тарифы системы, снижены размеры штрафа за неуплату сбора. Несмотря на то, что водители не смогли добиться своей главной цели - отмены платы за пользование федеральными дорогами, сообществу дальнобойщиков удалось институционализировать протест и организовать органы самоуправления. На фоне массового сопротивления водителей большегрузов было созданы профессиональные союзы, общественные организации. Наиболее крупная из них - общероссийская общественная организация содействия развитию автомобильных перевозок «Объединение перевозчиков России», включающая водителей из 43 регионов [Объединение Перевозчиков... web]. Конфликт вокруг «Платона» упорядочил связи и отношения между водителями и стал определяющим фактором становления их гражданского самосознания.

Качественные перемены в деятельности профессионального сообщества также произошли в Якутии, где была сформирована региональная ассоциация водителей-дальнобойщиков. Институционализация союза дальнобойщиков дала возможность водительскому сообществу легитимизировать функционирование структуры. Потенциальная возможность влияния на принятие решений активизировала процессы лоббирования мер по совершенствованию управления грузоперевозками на Севере и эффективной реализации деятельности предпринимателей, занятых транспортировкой грузов. Стоит отметить, что за время работы общественной организации возросло внимание к проблемам осуществления грузоперевозок в условиях Севера и Арктики. В апреле 2018 г. на совместном заседании Президиума экспертного Совета Государственной Думы Российской Федерации по вопросам законодательного обеспечения развития районов Крайнего Севера, приравненных к ним местностей, районов Дальнего Востока, а также территорий входящих в Арктическую зону с Торгово-промышленной палатой Российской Федерации были рассмотрены вопросы применения тахографов на автозимниках, обеспечение временных дорог местами стоянок для отдыха водителей - про- 
блемы, которые поднимает объединение дальнобойщиков Якутии.

Анализ практики взаимодействия водителей грузового транспорта с социумом показал, что значительное внимание сообщество якутских водителей большегрузов уделяет инициированию социальной активности. Помимо своих основных функций, связанных с обеспечением труднодоступных и отдаленных районов региона жизненно необходимыми товарами и услугами, дальнобойщики участвуют в общественно-полезной деятельности. Водители в улусах проводят социальные мероприятия, акции, благоустраивают общественные пространства, формируя тем самым инфраструктуру территории. Профессиональный опыт, глубокое практическое знание проблем населения Севера и Арктики, их положения, вероятно, побуждает у водителей желание помогать людям, стремление преобразовывать окружающую среду.

Любопытно также отметить тот факт, что водители нередко участвуют в агитационных мероприятиях. Очевидно, что сформированный в последние годы позитивный образ дальнобойщика напрямую влияет на укрепление авторитета водителей в обществе. Влияние дальнобойщиков в обществе активно используется в политических целях. Как показывает исследование, заинтересованность в сотрудничестве с водителями-дальнобойщиками выражают политические партии, лица на руководящих должностях в органах власти.

\section{Заключение}

В истории современной Якутии водители грузового транспорта стали одним из первых профессиональных сообществ, которые публично отстаивали свои корпоративные интересы и права.

Самоорганизация водителей-дальнобойщиков Республики Саха (Якутия) стала важнейшим фактором формирования гражданского сознания водителей грузового транспорта. Институционализация способствовала развитию профессионального этоса якутских дальнобойщиков, базирующегося на социальной ответственности перед обществом.
В долгосрочной перспективе требуют дальнейшего осмысления функции и деятельность профессиональных ассоциаций водителей, их социальные практики в связи с институционализацией. Значительный интерес отдельно представляет изучение гендерных особенностей водительского сообщества и семейных трудовых династий дальнобойщиков.

\section{СПИСОК ЛИТЕРАТУРЫ}

Акция протеста... web - Акция протеста нерюнгринских дальнобойщиков прервана и отложена до 25 февраля // http://www.1sn.ru/ 20762.html (дата обращения: 13.07.2020).

Алексеев web - Алексеев В. Философия «Платона» // https://mintrans.sakha.gov.ru/news/ front/view/id/2597455 (дата обращения: 12.07.2020).

Ассоциация дальнобойщиков... web - Ассоциация дальнобойщиков РС (Я): «Мы как одна большая семья» // http://portal.b14.ru/news/ assotsiatsiya-dalnobojshhikov-rs-ya-my-kakodna-bolshaya-semya (дата обращения: 14.07.2020).

Булчукей web - Булчукей $C$. Мудрые таттинские женщины помогли своим мужчинам объединиться // https://sakhalife.ru/mudryie-tattinskiezhenshhinyi-pomogli-svoim-muzhchinamobedinitsya (дата обращения: 13.07.2020).

Дальнобойщики Якутии... web - Дальнобойщики Якутии угрожают срывом северного завоза // https://yakutiamedia.ru/news/477501 (дата обращения: 14.07.2020).

Нерюнгри, Республика Саха-Якутия web - Нерюнгри, Республика Саха-Якутия. Веб-форум Межрегиональной общественной организации автомобилистов «Свобода выбора» // https://www.19may.ru/forum/archive/ index.php/t-10496.html (дата обращения: 16.07.2020).

Объединение Перевозчиков... web - Объединение Перевозчиков России // https://opr.com.ru/ company (дата обращения: 16.07.2020).

Погребняк web - Погребняк М. Запуск «Платона». В России начала работать новая система по взиманию денег с дальнобойщиков // https:// meduza.io/feature/2015/11/16/platon-ne-drug (дата обращения: 16.07.2020).

Предприниматели Таттинского улуса... web - Предприниматели Таттинского улуса активно участвуют в социально-экономической жизни улуса // https://www.sakha.gov.ru/news/front/ view/id/3172773 (дата обращения: 16.07.2020). 
Сборов web-Сборов А. Грузовики выехали на обочину. Акция протеста дальнобойщиков не обошлась без жертв // https://www.kommersant.ru/ doc/2857900 (дата обращения: 16.07.2020).

Сводный годовой доклад... web - Сводный годовой доклад о ходе реализации и оценке эффективности программ Республики Саха (Якутия) // https://mintrans.sakha.gov.ru/ deyat/Gosudarstvennie-i-tselevie-programmi/ svodnyj-godovoj-doklad-o-hode-realizatsii-iotsenke-effektivnosti-programm-respublikisaha-jakutija (дата обращения: 12.07.2020).

Состоялся 1-й Съезд... web - Состоялся 1-й Съезд дальнобойщиков Якутии // https://mintrans. sakha.gov.ru/news/front/view/id/2760613 (дата обращения: 13.07.2020).

Указ Главы РС (Я) от 06.11.2019... web - Указ Главы РС (Я) от 06.11.2019 № 804 «О государственной программе Республики Саха (Якутия) “Обеспечение безопасности жизнедеятельности населения Республики Саха (Якутия) на 20202024 годы"» // http://publication.pravo.gov.ru/ Document/View/1400201911140001 (дата обращения: 16.07.2020).

Якутские дальнобойщики... web - Якутские дальнобойщики бастуют против платы за проезд по федеральным трассам // https:// yakutiamedia.ru/news/475721 (дата обращения: $13.07 .2020)$.

Argounova-Low 2012 - Argounova-Low T. Roads and Roadlessness: Driving trucks in Siberia // Journal of Ethnology and Folkloristics. 2012. № 6 (1). P. 71-88.

\section{REFERENCES}

Protest Action of Neryungri Truck-Drivers Was Stopped and Delayed Until 25 February. URL: http://www.1sn.ru/20762.html (accessed 13 July 2020).

Alekseev V. "Platon” Philosophy. URL: https:// mintrans.sakha.gov.ru/news/front/view/id/ 2597455 (accessed 12 July 2020).

Truck-Drivers Association of $R S(Y)$ : «We are One Big Family». URL: http://portal.b14.ru/news/ assotsiatsiya-dalnobojshhikov-rs-ya-my-kakodna-bolshaya-semya (accessed 14 July 2020).

Bulchukei S. Wise Tattinsky Women Helped Their Men to Join Together. URL: https://sakhalife.ru/ mudryie-tattinskie-zhenshhinyi-pomogli-svoim- muzhchinam-obedinitsya (accessed 13 July 2020).

Truck-Drivers of Yakutia Threatening to Derail the Northern Supply. URL: https://yakutiamedia.ru/ news/477501 (accessed 14 July 2020).

Neryungri, Republic of Sakha-Yakutia. Web-Forum of Interregional Non-Governmental Organization of Drivers "The Freedom of Choice». URL: https://www.19may.ru/forum/ archive/index.php/t-10496.html (accessed 16 July 2020).

Association of Russian Carriers. URL: https:// opr.com.ru/company (accessed 16 July 2020).

Pogrebnyak M. The Launch of "Platon". New Fee System for Truck-Drivers Has Been Started in Russia. URL: https://meduza.io/feature/2015/11/ 16/platon-ne-drug (accessed 16 July 2020).

Entrepreneurs of Tattinsky District Participate Actively in Socio-Economic Life of the District. URL: https://www.sakha.gov.ru/news/front/ view/id/3172773 (accessed 16 July 2020).

Sborov A. Trucks Leaving the Side of the Road. Protest Action of Truck-Driversnot Without Casualties. URL: https://www.kommersant.ru/ doc/2857900 (accessed 16 July 2020).

Annual Consolidated Report on the Implementation and Effectiveness Evaluation of Republic of Sakha (Yakutia) Programs. URL: https://mintrans. sakha.gov.ru/deyat/Gosudarstvennie-i-tselevieprogrammi/svodnyj-godovoj-doklad-o-hoderealizatsii-i-otsenke-effektivnosti-programmrespubliki-saha-jakutija (accessed 12 July 2020).

The $1^{\text {st }}$ Congress of Yakutian Truck-Drivers Had Taken Place. URL: https://mintrans.sakha. gov.ru/news/front/view/id/2760613 (accessed 13 July 2020).

Order of the Glava of RS (Y) 06.11.2019 № 804 "On the State Program of Republic of Sakha (Yakutia) 'Security and the Livelihoods of the Population of Republic of Sakha (Yakutia) for Period 2020-2024' '. URL: http://publication. pravo.gov.ru/Document/View/1400201 911140001(accessed 16 July 2020).

Yakutian Truck-Drivers Protesting Against Fees for Using Federal Roads. URL: https:// yakutiamedia.ru/news/475721 (accessed 13 July 2020).

Argounova-Low T., 2012. Roads and Roadlessness: Driving Trucks in Siberia. Journal of Ethnology and Folkloristics, no. 6 (1), pp. 71-88. 


\section{СОЦИОЛОГИЯ И СОЦИАЛЬНЫЕ ТЕХНОЛОГИИ}

\section{Information About the Author}

Maria E. Osipova, Candidate for a Degree, Department of Sociology and Human Resources Management, M.K. Ammosov North-Eastern Federal University, Belinskogo St, 58, 677000 Yakutsk, Russian Federation, marios1692@mail.ru, https://orcid.org/0000-0001-5455-3944

\section{Информация об авторе}

Мария Егоровна Осипова, соискатель кафедры социологии и управления персоналом, Северо-Восточный федеральный университет им. М.К. Аммосова, ул. Белинского, 58, 677000 г. Якутск, Российская Федерация, marios1692@mail.ru, https://orcid.org/0000-0001-5455-3944 